\title{
Application of additive technologies for synthesis of titanium alloys of Ti-Al, Ti-Al-Nb systems of elemental powders ${ }^{a}$
}

\author{
Alexey Grigoryev ${ }^{1}$, Igor Polozov², Anatoliy Popovich ${ }^{2}$, and Vadim Sufiyarov ${ }^{2}$ \\ ${ }^{1}$ JSC "ODK-Klimov", 194100, Kantemirovskaya st., 11, Russian Federation \\ 2 The Center of the National Technology Initiative (NTI) "New Production Technologies", Peter the \\ Great St. Petersburg Polytechnic University, 195251, Polytechnicheskaya st., 29, Russian Federation
}

\begin{abstract}
Additive technologies are one of the drivers for development of new industrial revolution. For developing additive production it is necessary to expand the nomenclature of materials used in the form of powders. One of the ways for synthesizing new alloys in additive technologies is applying a mixture of powders as primary components; the powders correspond in their composition to the given alloy. The technology of selective laser melting enables synthesizing the necessary alloy by means of layer by layer melting of a powder mixture. A study of the process of Ti-5Al and Ti-6Al$7 \mathrm{Nb}$ titanium alloys synthesis of elemental powders by means of selective laser melting was undertaken in this work. Microstructure, chemical composition, mechanical properties of the synthesized alloys were studied and also the influence of thermal processing on the microstructure of the Ti$6 \mathrm{Al}-7 \mathrm{Nb}$ alloy obtained of elemental powders was explored.
\end{abstract}

\section{Introduction}

Modern rate of industrial development requires implementing progressive methods of producing metal ware. One of them is additive technologies which combine using digital projecting for creating a computer model of the future workpiece and manufacturing the piece itself by means of adding the material layer by layer on special equipment [1]. Additive production is one of drivers which has an impact on developing the concept "Industry 4.0" and which is now actively used for making the products. Nevertheless, for full implementation of the new production concept it is necessary to further improve additive technologies. One of the directions for development is expanding the nomenclature of materials used in additive production.

Selective laser melting of powders is one of the most widespread and promising methods for producing metal ware by means of adding the material layer by layer. Metal powders are used as primary materials in the technology of selective laser melting. Powders for additive technologies, as a rule, are produced with the help of gas and plasma atomization of melt

${ }^{a}$ The research was carried out with financial support of the Russian Science Foundation (grant project No. 18-13-00111)

*Corresponding author: polozov ia@spbstu.ru 
mass. In connection with difficulties in producing powders of complex alloys for additive technologies the nomenclature of commercially available powders for additive production is significantly limited at the moment.

The decision for this problem can be found while applying alternative methods for producing items of titanium alloys with the help of additive technologies. One of such directions is using a mechanical mixture of powders of separate elements of the alloy for producing items by means of layer synthesis, as the result of which in-situ synthesis of the required alloy will be made. At present there are works which describe the results of studies devoted to layer synthesis of alloys of such systems as Ti-Nb [2], Al-Si [3], Mg-Al [4]. The presented works as a rule demonstrate that the selective laser melting (SLM) method may be successfully used for in-situ synthesis of alloys that are unavailable in the form of prealloyed powder.

Titanium alloys are widely used in various branches of industry, for example, for manufacturing aviation equipment parts thanks to their high strength-to-weight ratio, corrosion stability and ability to be used at relatively high temperatures. Over the last years the tendency for increasing the titanium parts percent as compared with the total mass of a gas turbine engine. In connection with that using additive technologies for synthesizing titanium alloys is of great interest for industry.

The goal of the present work was to undertake a study and evaluate the possibility of layer by layer synthesis of titanium alloys of different types of elemental powders by means of selective laser melting. With the use of powder mixtures the composition of which corresponds to Ti-5Al and Ti-6Al-7Nb alloys, compact samples were synthesized, a study was undertaken including the microstructure, phase composition as a primary material and the material after thermal processing, and also mechanical properties of the synthesized alloys were estimated.

\section{Materials and working procedure}

For studying the process of in-situ synthesis of titanium alloys of elemental powders three alloys were chosen: Ti-5Al (\%, mass.) and Ti-6Al-7Nb (\%, mass.). Titanium powders (CP Ti Grade 2, analogue of BT1-0), aluminum powders (99.9\% purity) and niobium powders (NBP-1a grade, $99.7 \%$ purity) were used as primary powder materials for preparing powder mixtures. Ti and $\mathrm{Al}$ powder particles have a spherical shape, while $\mathrm{Nb}$ powder particles have a comminuted shape. Grain fineness of metal powders was determined by method of laser diffraction on the particle size measurement instrument Analysette 22 NanoTec plus (Fig. 2.2) with the total measurement range $0.01-2000 \mu \mathrm{m}$. Data on the grain fineness of primary powders are given in Table 1.

Table 1. Grain fineness of primary powders.

\begin{tabular}{|l|l|l|l|}
\hline Powder & $\mathbf{d} \mathbf{1 0}, \boldsymbol{\mu m}$ & $\mathbf{d} \mathbf{5 0}, \boldsymbol{\mu m}$ & $\mathbf{d} \mathbf{9 0}, \boldsymbol{\mu m}$ \\
\hline $\mathrm{Ti}$ & 23.8 & 44.6 & 76.1 \\
\hline $\mathrm{Al}$ & 8.5 & 21.2 & 41.1 \\
\hline $\mathrm{Nb}$ & 15.1 & 32.9 & 65.1 \\
\hline
\end{tabular}

Powder mixtures were prepared of primary powder components with the use of the laboratory gravity mixer in the course of 12 hours. The time for mixing the powder components was selected in such a way as to provide for equal distribution of separate components in the powder mixture.

For synthesizing the samples by means of laser melting a SLM $280 \mathrm{HL}$ set was used manufactured by SLM Solutions GmbH. Synthesis of compact samples is implemented on 
the main platform. A thin layer of powder material is applied to it. The layer is applied with the help of a special moving block which is filled with powder. This block batches the powder material while moving over the platform surface and the powder layer is distributed and leveled over the surface with the use of a silicone squeegee. Then the layer is processed with laser emission. The laser beam is focused on the surface of the powder layer creating a spot of a small diameter. With the help of a mirror system the laser beam is deflected and moved over the layer surface in accordance with the file created earlier. By means of laser emission the powder material is melted and then a solid phase structure is formed and at the same time the current layer is alloyed with the previous one. After that the platform is lowered to the height equal to the thickness of the powder layer, a new layer of the powder is applied and the process is repeated until all the layers have been processed. Synthesis of the samples was implemented in argon atmosphere.

The SLM 280HL set has two ytterbium fiber lasers with the wave length equal to $1.07 \mu \mathrm{m}$ and the maximum power of $400 \mathrm{~W}$ and $1 \mathrm{~kW}$. The laser with the maximum power of $400 \mathrm{~W}$ has a focusing spot with the diameter of $80 \mu \mathrm{m}$ and Gaussian distribution of power over the spot, and the laser with the maximum power of $1 \mathrm{~kW}$ has a focusing spot with the diameter of $700 \mu \mathrm{m}$ with equal distribution of power.

For studying the microstructure, phase composition of the synthesized material samples with the size of 10x10x10 mm were made. For running mechanical tests cylindrical blanks were made with the diameter of $12 \mathrm{~mm}$ and height of $90 \mathrm{~mm}$, then samples for tensile tests were ground out them by means of mechanical processing according to GOST 1497-84 "Metals. Methods of tensile tests". The meanings of the basic parameters of the SLM process used for sample synthesis are in table 2

Table 2. Parameter values of the SLM process used for the synthesis of compact samples.

\begin{tabular}{|l|l|l|l|l|l|}
\hline $\begin{array}{l}\text { Laser } \\
\text { profile }\end{array}$ & $\begin{array}{l}\text { Laser } \\
\text { power, } \\
\mathbf{W}\end{array}$ & $\begin{array}{l}\text { Scanning } \\
\text { speed, } \\
\mathbf{m m} / \mathbf{s}\end{array}$ & $\begin{array}{l}\text { Distance } \\
\text { between } \\
\text { laser } \\
\text { passes, } \\
\boldsymbol{\mu m}\end{array}$ & $\begin{array}{l}\text { Layer } \\
\text { thickness, } \\
\boldsymbol{\mu m}\end{array}$ & $\begin{array}{l}\text { Laser } \\
\text { spot } \\
\text { diameter, } \\
\boldsymbol{\mu m}\end{array}$ \\
\hline Gaussian & $245-305$ & $755-855$ & $90-150$ & 50 & $\sim 80$ \\
\hline equal & $650-950$ & $250-350$ & $450-550$ & 100 & $\sim 700$ \\
\hline
\end{tabular}

A study of the microstructure of compact samples was undertaken on a scanning electronic microscope (SEM) TESCAN Mira 3 LMU both in secondary electrons and in backward scattered electrons. This microscope has an attachment for performing energy dispersive X-ray spectroscopy (EDS) which was used for the spot analysis of chemical composition of compact samples and for obtaining data on distribution of chemical elements in the sample.

The analysis of phase composition of the samples was made with the use of a Bruker D8 Advance diffractometer on which X-ray patterns of the samples on $\mathrm{CuK} \alpha(\lambda=1,5418 \AA)$ emission were obtained.

Testing of mechanical properties of the samples for tensile breakage at ambient and elevated temperatures was performed in accordance with GOST 1497-84 (ISO 6892 "Metallic materials - Tensile testing") and GOST 9651-84 (ISO 783 "Metals. Methods of tension tests at elevated temperature") on the Zwick/Roell Z050 testing machine.

Thermal processing of the synthesized samples of Ti-5Al alloy was implemented in a MTI VBF-1200X vacuum furnace. Annealing at $750{ }^{\circ} \mathrm{C}$ and 1 hour equalizing was implemented with further after cooling with the furnace to the ambient temperature. Thermal processing of synthesized samples of Ti-6Al-7Nb alloy was made in the KJ-1700X muffle furnace. The samples were previously placed in quartz tubes where high vacuum was 
prepared. The samples annealing was implemented at temperatures from $1050{ }^{\circ} \mathrm{C}$ to $1350{ }^{\circ} \mathrm{C}$ with equalizing from 1 to 3.5 hours and after cooling in a furnace.

\section{Results and discussions}

Powder mixture of Ti-5Al alloy after mixing for 12 hours is displayed in Fig. 1. Particles of titanium and aluminum powders have preserved spherical shape after mixing that is important for plasticity of a powder mixture. Aluminum particles are smaller in comparison with titanium powder particles and are equally distributed in the powder mixture. At that, in some places there is coagulation of separate finely dispersed aluminum particles.

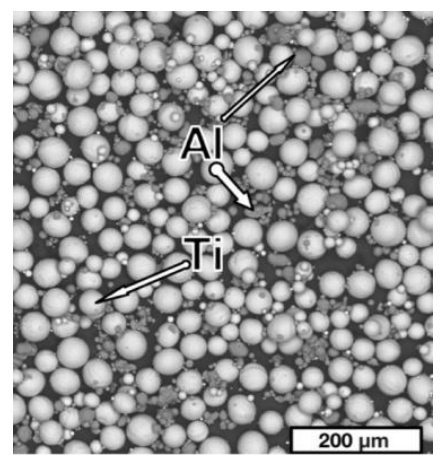

Fig. 1. An image of powder mixture of Ti-5 Al alloy.

Images of etched grinding surface of compact samples of Ti-5Al alloy made on the scanning electronic microscope (SEM) in backward scattered electrons are presented in Fig. 2. There are no sections with unmelted particles of Ti or Al elements. Relative density of the compact material measured by means of hydrostatic weighing is $98.97 \pm 0.07 \%$. EDS analysis of the sample along the line (Fig. 2, b) (and in separate points of the sample (table 3), specified in Fig. 2, a, indicates that complete decomposition of $\mathrm{Al}$ in Ti matrix has taken place. Chemical composition of synthesized samples corresponds to the required one.

(a)

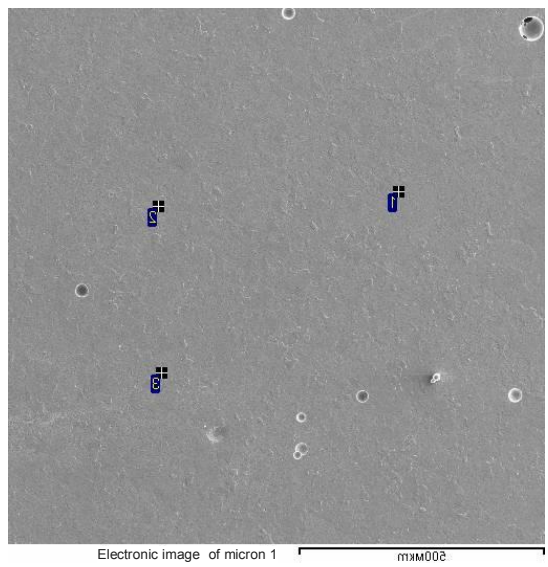

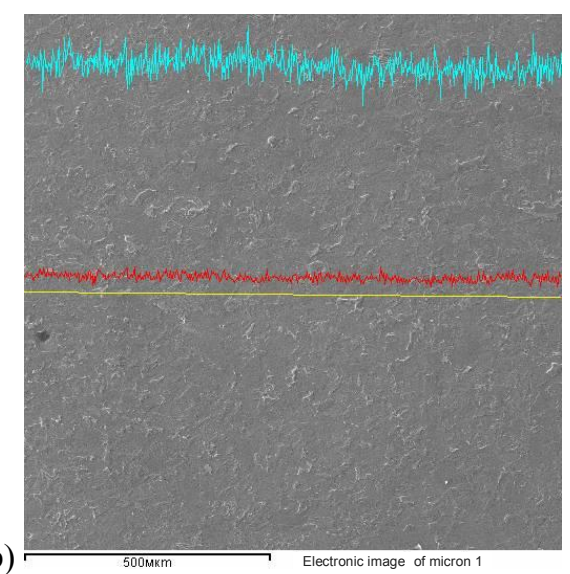

(b)

Fig. 2. SEM-images of the etched grinding surface of samples made of Ti-5 Al alloy powder mixture at laser power $275 \mathrm{~W}$ (a) and $950 \mathrm{~W}$ (b). 
Table 3. Results of the analysis of chemical composition by means of energy dispersive X-ray spectroscopy of Ti-5 Al samples made by means of SLM in separate points of the samples.

\begin{tabular}{|c|c|c|c|}
\hline $\begin{array}{l}\text { Laser power, } \\
\mathrm{W}\end{array}$ & Point & Al, mass. \% & Ti, mass. \% \\
\hline \multirow{3}{*}{275} & 1 & 4.9 & 95.1 \\
\cline { 2 - 4 } & 2 & 4.9 & 95.1 \\
\cline { 2 - 4 } & 3 & 5.0 & 95.0 \\
\hline \multirow{3}{*}{950} & 1 & 4.4 & 95.6 \\
\cline { 2 - 4 } & 2 & 4.5 & 95.50 \\
\cline { 2 - 4 } & 3 & 4.2 & 95.8 \\
\hline
\end{tabular}

After having been mixed in gravity mixer the powder mixture of Ti-6Al-7Nb alloy was used for synthesis of compact samples by means of SLM. In the process of SLM of Ti-6Al$7 \mathrm{Nb}$ powder mixture titanium, aluminum particles were melted and niobium particles were partially melted (Fig. 3). The structure of synthesized material is solid solution of alloying elements in titanium with separate niobium particles. EDX analysis results (table 4) in different points of the sample indicated that composition of the areas where there are no separate $\mathrm{Nb}$ particles includes both $\mathrm{Al}$ and $\mathrm{Nb}$ in the quantity close to the composition of the initial mixture, white areas correspond to niobium. Maximum relative density of the synthesized material is $98.9 \%$.

(a)

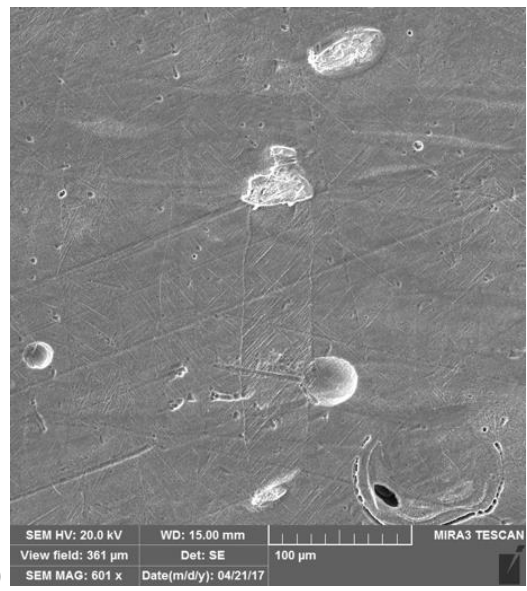

(b)

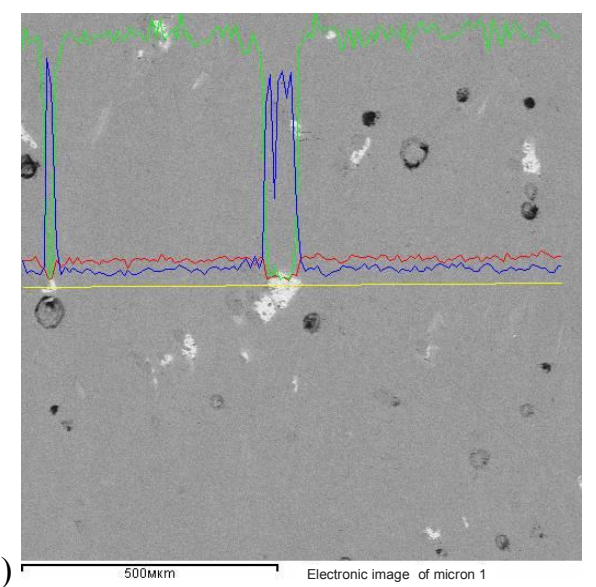

Fig. 3. SEM-images of the etched grinding surface of a sample made of Ti-6Al-7Nb alloy powder mixture at laser power $950 \mathrm{~W}$.

Table 4. Results of the analysis of chemical composition by means of energy dispersive X-ray spectroscopy of a Ti-6Al-7Nb sample made by means of SLM in various points of the sample.

\begin{tabular}{|l|l|l|l|}
\hline Point & $\mathrm{Nb}, \%$ & $\mathrm{Al}, \%$ & $\mathrm{Ti}, \%$ \\
\hline 1 & 98.23 & 0.23 & 1.54 \\
\hline 2 & 94.19 & 0.53 & 5.29 \\
\hline 3 & 7.21 & 6.53 & 86.26 \\
\hline 4 & 5.43 & 5.92 & 88.64 \\
\hline
\end{tabular}


For dissolving $\mathrm{Nb}$ particles and obtaining a more equal chemical composition in the synthesized material thermal processing was performed in the form of annealing in different modes. Microstructure of the material after annealing is shown in Fig. 4. At the annealing temperature lower than $1350{ }^{\circ} \mathrm{C} \mathrm{Nb}$ particles haven't dissolved in the matrix. At $1350{ }^{\circ} \mathrm{C}$ and 3.5 hours equalizing separate $\mathrm{Nb}$ particles are not present. The material has $(\alpha+\beta)$-platelike microstructure. Presence of these phases is confirmed by the results of X-ray phase analysis (Fig. 4). When thermal processing temperature is increased volume fraction of the beta-phase and average thickness of alpha-phase plates is also increased.

(a)
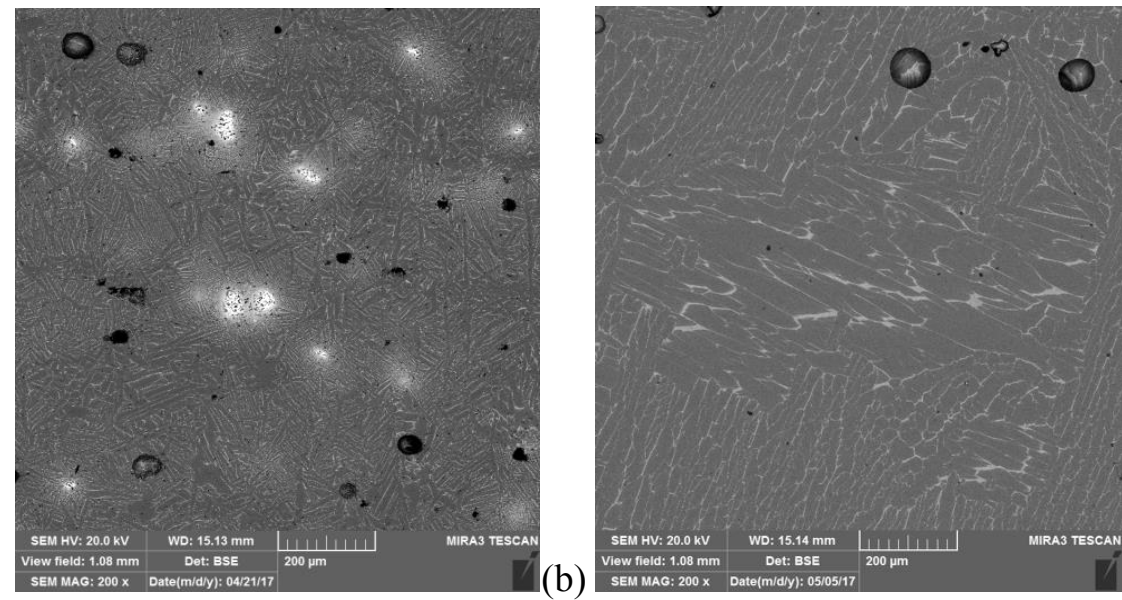

(c)

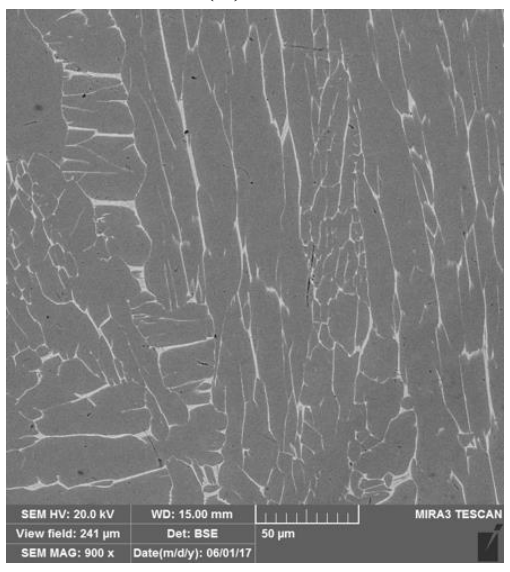

Fig. 4. Microstructure of samples made of Ti-6Al-7Nb alloy after annealing: (a) $1050{ }^{\circ} \mathrm{C}, 1$ hour; (b) $1350{ }^{\circ} \mathrm{C}, 2.5$ hours; (c) $13500^{\circ} \mathrm{C}, 3.5$ hours

Results of mechanical tests of the Ti-5Al and Ti-6Al-7Nb alloy samples are given in table 5. At ambient temperature, strength limit of samples of Ti-5Al alloy after annealing at 750 ${ }^{\circ} \mathrm{C}$ for 1 hour is $897 \pm 7 \mathrm{MPa}$ with percentage extension $-5.0 \pm 1.2 \%$, and that is compatible with properties of the samples made according to traditional methods. Strength limit at 400 ${ }^{\circ} \mathrm{C}$ is $521 \pm 12 \mathrm{MPa}$ exceeding strength limit of a cast sample and is at the level of a deformable sample of BT5 alloy. In the case of Ti-6Al-7Nb alloy yield tensile strength and strength limit of samples after annealing is 770 and $850 \mathrm{MPa}$ respectively at $2 \%$ tensile elongation. These values are lower than those of the material made by means of selective laser melting of prealloyed powder of this alloy. Reduced mechanical characteristics may be connected with a large amount of cavities in the material. 
Table 5. Mechanical properties of Ti-5Al and Ti-6Al-7Nb alloys synthesized by means of selective laser melting of elemental powders and comparing them with the properties of samples made according to other technologies.

\begin{tabular}{|c|c|c|c|c|c|}
\hline $\begin{array}{c}\text { Testing } \\
\text { temperature, } \\
{ }^{\circ} \mathrm{C}\end{array}$ & Alloy & $\begin{array}{c}\text { Yield } \\
\text { tensile } \\
\text { strength, } \\
\mathrm{MPa}\end{array}$ & $\begin{array}{c}\text { Strength } \\
\text { limit, } \mathrm{MPa}\end{array}$ & $\begin{array}{l}\text { Percentage } \\
\text { extension, \% }\end{array}$ & $\begin{array}{c}\text { Source of } \\
\text { data }\end{array}$ \\
\hline \multirow[t]{3}{*}{20} & $\begin{array}{l}\mathrm{Ti}+5 \mathrm{Al} \text { (selective } \\
\text { laser melting and } \\
\text { annealing) }\end{array}$ & $855 \pm 15$ & $897 \pm 7$ & $5.0 \pm 1.2$ & $\begin{array}{l}\text { The given } \\
\text { study }\end{array}$ \\
\hline & ВТ5Л & - & 800 & 6 & [5] \\
\hline & $\begin{array}{l}\text { BT5 deformable } \\
\text { annealed }\end{array}$ & - & $685-735$ & $6-8$ & {$[6]$} \\
\hline \multirow[t]{2}{*}{400} & $\begin{array}{l}\mathrm{Ti}+5 \mathrm{Al} \text { (selective } \\
\text { laser melting and } \\
\text { annealing) }\end{array}$ & $412 \pm 10$ & $521 \pm 12$ & $9.7 \pm 1.1$ & $\begin{array}{c}\text { The given } \\
\text { study }\end{array}$ \\
\hline & $\begin{array}{l}\text { BT5 deformable } \\
\text { annealed }\end{array}$ & - & 520 & - & {$[5]$} \\
\hline \multirow[t]{3}{*}{20} & $\begin{array}{c}\mathrm{Ti}+6 \mathrm{Al}+7 \mathrm{Nb} \\
\text { (selective laser } \\
\text { melting of powder } \\
\text { mixture and } \\
\text { annealing) }\end{array}$ & $774 \pm 10$ & $850 \pm 10$ & $2.0 \pm 0.2$ & $\begin{array}{c}\text { The given } \\
\text { study }\end{array}$ \\
\hline & $\begin{array}{l}\text { Ti-6Al-7Nb } \\
\text { (selective laser } \\
\text { melting of } \\
\text { prealloyed } \\
\text { powder and } \\
\text { annealing) } \\
\end{array}$ & $1360 \pm 30$ & $1480 \pm 26$ & $1.4 \pm 0.6$ & [7] \\
\hline & BT6 (fritting) & 740 & 830 & 5 & {$[5]$} \\
\hline
\end{tabular}

\section{Conclusions}

4.1 By means of SLM it is possible to synthesize $\alpha$-titanium alloy (BT5) of elemental $\mathrm{Ti}$ and $\mathrm{Al}$ powders with homogeneous distribution of chemical elements and high mechanical properties. Microstructure of the obtained alloy consists of $\alpha$-Ti equiaxial grains of various sizes. Strength limit is $897 \pm 7 \mathrm{MPa}$, percentage extension $-5.0 \pm 1.2 \%$.

4.2 With the help of the SLM method it is possible to synthesize Ti-6Al-7Nb alloy of elemental powders, however in the initial state there are separate unmelted $\mathrm{Nb}$ particles in the material inside the areas with equal distribution of $\mathrm{Ti}, \mathrm{Al}, \mathrm{Nb}$ of the specified composition.

4.3 In the initial state Ti-6Al-7Nb alloy microstructure has the form of finely dispersed precipitation of needle-shaped martensite with separate $\mathrm{Nb}$ particles. After $\mathrm{H} / \mathrm{T}(\alpha+\beta)$-plate like structure is formed. $\mathrm{Nb}$ particles dissolving takes place at $1350{ }^{\circ} \mathrm{C}$ annealing. Strength limit of the samples is $850 \mathrm{Mpa}$ at percentage extension equal to $2 \%$.

\section{References}

1. H. Gaub, Reinforced Plastics, 60(6) (2016)

2. M. Fischer, et al. Materials Science and Engineering, (62) (2016)

3. P. Vora, et al. Additive manufacturing, 7 (2015) 
4. E. O. Olakanmi, Journal of Materials Processing Technology 213(8) (2013)

5. B. N. Arzamasov, T. V. Solovyeva, S. A. Gerasimov, Spravochnik po konstruktsionnym materialam [Handbook of structural materials] (MGTU Baumana Publ., Moscow 2005)

6. Federal Standard GOST 26492-85 "Titanium and titanium alloys rolled bars".

7. E. Chlebus, et al. Materials Characterization 62(5) (2011) 